TINJAUAN PUSTAKA

\title{
Peranan Anestesiologis di Laboratorium Katerisasi Kardiak: Perspektif Ahli Jantung
}

\section{The Role of Anesthesiologist in Cardiac Catheterization Laboratory: Cardiologist Perspective}

\author{
Sidhi Laksono Purwowiyoto ${ }^{\square *}$,** $^{*}$ Arly Ihvaricci Siswitono***, Reynaldo Halomoan \\ Siregar ${ }^{* * * *}$ \\ *Laboratorium Kateterisasi Jantung, SMF Jantung, RSUD Pasar Rebo, Jakarta Timur, Indonesia \\ ${ }^{* *}$ Fakultas Kedokteran, Universitas Muhammadiyah Prof. DR. Hamka, Tangerang, Indonesia \\ ${ }^{* * *}$ SMF Anestesi, RSUD Pasar Rebo, Jakarta Timur, Indonesia \\ ${ }^{* * * * *}$ Fakultas Kedokteran, Universitas Katolik Indonesia Atmajaya, Jakarta Utara, Indonesia \\ ${ }^{\bowtie}$ Korespondensi: $\underline{\text { sidhilaksono@uhamka.ac.id }}$
}

\begin{abstract}
The prevalence of morbidity and mortality due to cardiovascular disease globally is still high. This will have an impact on the growing role of the cardiac catheterization laboratory (CCL) in hospital services. The implementation of catheterization in CCL requires the role of anesthesiologists, especially in procedures that require general anesthesia because of the patient's needs, long duration, and complexity of the procedure. The presence of anesthesiologists in carrying out actions at CCL also helps the cardiologist to focus on the actions taken. The work area in CCL can be different from the operating theater in general and an anesthesiologist's understanding of this is very important in providing good anesthesia care. Good anesthesiological competence and collaboration with cardiologists in implementing procedures will reduce the risk of patient morbidity and mortality.
\end{abstract}

Keywords: anesthesia planning; anesthesia technique; cardiac catheterization laboratory; cardiologist; role of anesthesiologist 


\begin{abstract}
ABSTRAK
Prevalensi morbiditas dan mortalitas akibat penyakit kardiovaskular secara global masih tinggi. Hal ini akan berdampak terhadap semakin berkembangnya peran laboratorium katerisasi kardiak (LKK) dalam pelayanan di rumah sakit. Pelaksanaan kateterisasi di LKK membutuhkan peran anestesiolog terutama pada prosedur yang membutuhkan anestesi umum karena kebutuhan pasien, durasi yang panjang, dan kompleksitas prosedur. Kehadiran anestesiolog dalam pelaksanaan tindakan di LKK juga membantu kardiolog untuk fokus pada tindakan yang dilakukan. Area kerja di LKK dapat berbeda dengan ruang operasi pada umumnya dan pemahaman anestesiolog terhadap hal ini sangat penting dalam memberikan perawatan anestesi yang baik. Kompetensi anestesiolog yang baik dan kerjasama dengan kardiolog dalam pelaksanaan prosedur akan mengurangi risiko morbiditas dan mortalitas pasien.
\end{abstract}

Kata kunci: kardiologis; laboratorium kateterisasi kardiak; peranan anestesiolog; perencanaan anestesia; teknik anestesia

\section{PENDAHULUAN}

Penggunaan laboratorium katerisasi kardiak (LKK) sangat penting untuk berbagai tindakan baik diagnostik ataupun terapeutik pada penyakit kardiovaskular. Secara global, kasus kardiovaskular diperkirakan mencapai 422,7 juta kasus dengan kematian sebesar 17.92 juta. ${ }^{1} \quad$ Meningkatnya prevalensi penyakit arteri koroner juga akan meningkatkan kebutuhan untuk laboratorium katerisasi kardiak. Dalam menjalani prosedur, peran anestesiolog di LKK menjadi penting karena banyak pasien memerlukan anestesi karena faktor umur, komorbid serta durasi dari prosedur. Selain itu, peran anestesiolog juga penting karena perlunya pemahaman akan obat-obat anestesi yang akan digunakan dan efeknya pada perubahan fisiologis yang terjadi.

\section{LINGKUNGAN KERJA LKK}

Lingkungan kerja di LKK dapat berbeda dibandingkan ruangan tindakan lainnya. Di dalam LKK, terdapat banyak peralatan yang digunakan untuk menunjang prosedur seperti $c$-arm. Hal ini dapat mempengaruhi kinerja anestesiolog karena mungkin tidak terbiasa dengan lingkungan di LKK dan peralatan anestesi sering berada dibelakang alat pencitraan sehingga dapat membatasi area kerja pada pasien. Selain itu, terdapat risiko terpapar radiasi yang dapat mempengaruhi fisiologis tubuh. Paparan radiasi dapat meningkatkan risiko terkena kanker (otak, tiroid, dan kulit), risiko cacat lahir, dan infertilitas. ${ }^{2}$ Berdasarkan Komisi Internasional tentang Perlindungan Radiologis, batas paparan radiasi pengion pada personel adalah $20 \mathrm{mS}$ per tahun, dengan rata-rata 5 tahun, dengan batas maksimal tahunan sebesar $50 \mathrm{mS}^{3}$ Oleh karena itu, penting untuk memakai alat pelindung seperti apron, pelindung tiroid, dan penutup kepala untuk meminimalisir paparan radiasi. Pemilihan teknik anestesi seperti anestesia intravena total (TIVA) dapat dipertimbangkan untuk meminimalisir paparan radiasi pada anestesiolog karena dapat mengurangi intensitas radiasi dengan menjaga jarak. ${ }^{4}$ Gambar 1 memperlihatkan posisi tenaga kesehatan dan peralatan dalam prosedur tindakan kateterisasi jantung. 


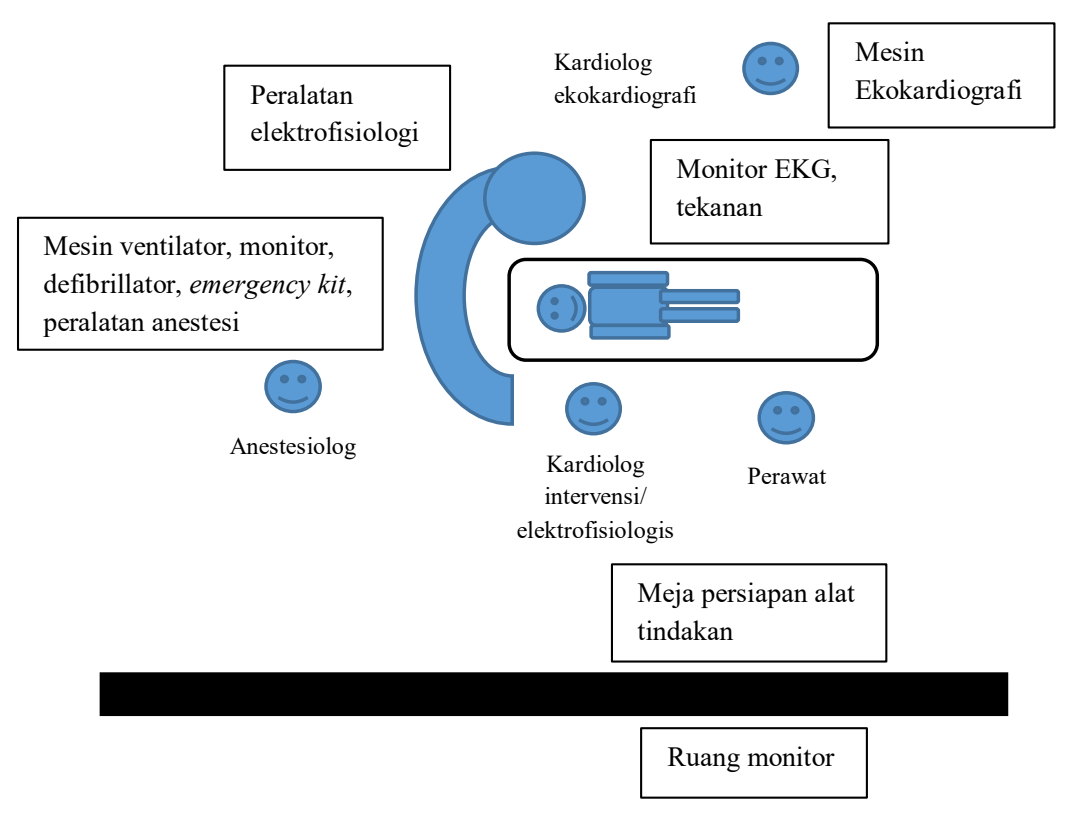

Gambar 1. Posisi tenaga kesehatan dan peralatan dalam prosedur kateterisasi jantung.

\section{PERAN ANESTESIOLOG}

Seorang anestesiolog berperan penting dalam prosedur di LKK terutama dalam kondisi darurat ataupun hemodinamika yang tidak stabil. Kehadiran anestesiolog dapat melakukan pemantauan dan memberikan tatalaksana terkait. Dalam beberapa prosedur device closure pada pasien pediatrik juga membutuhkan anestesi umum dengan ventilasi yang terkontrol. Pemasangan implan defibrillator juga memerlukan teknik anestesi umum dengan pemasangan selang endotrakeal. Secara umum, setiap tindakan elektif di LKK akan membutuhkan konsultasi pre-tindakan kepada anestesiolog untuk menilai risiko pada pasien serta pemilihan teknik anestesi. Dalam kondisi pasien yang tidak stabil, kehadiran anestesiolog dapat memberikan penanganan sehingga kardiolog dapat fokus pada prosedur. Pemasangan jalur intravena, memimpin prosedur resusitasi jantung paru, serta kardioversi ataupun defibrilasi. Peran anestesiolog sangat penting dalam kondisi pasien dengan gangguan perkembangan, demensia, serta gangguan cemas karena mungkin membutuhkan dosis sedasi yang berbeda. ${ }^{6,7}$

\section{PERENCANAAN ANESTESI}

Persiapan prosedur dimulai dengan memastikan persediaan obat dan peralatan yang mendukung seperti agen anestesi, heparin, protamin, syringe, set infus, kateter vena sentral, defibrillator, peralatan yang menunjang jalan napas, serta alat monitor untuk memantau hemodinamika pasien. Evaluasi pasien sebelum prosedur penting untuk menghindari komplikasi akibat administrasi obat-obatan anestesi serta mengetahui komorbid pasien. Evaluasi terdiri dari anamnesis meliputi riwayat prosedur yang menggunakan agen anestesi, riwayat alergi, riwayat pengobatan rutin, riwayat penyakit sistemik, serta riwayat kebiasaan. Selain melalui anamnesis, pemeriksaan fisik juga penting untuk mengetahui adanya abnormalitas dari kondisi pasien serta 
pemeriksaan jalan napas untuk mengamankan jalan napas selama prosedur jika diperlukan. Pemeriksaan penunjang seperti pemeriksaan darah rutin sering dilakukan untuk mengetahui kelayakan pelaksanaan prosedur pada pasien. Pemeriksaan dengan ekokardiografi juga dapat dilakukan sebelum prosedur. ${ }^{7}$

Tabel 1. Obat-obatan yang perlu disiapkan dalam pelaksanaan prosedur di LKK

\begin{tabular}{|c|c|c|}
\hline Nama obat & Dosis & Indikasi \\
\hline Adrenalin & $1 \mathrm{mg}$ & $\begin{array}{l}\text { Henti jantung, reaksi } \\
\text { anafilaksis }\end{array}$ \\
\hline Atropin & $0.12 \mathrm{mg} / \mathrm{kg}$ & Bradikardia \\
\hline Amiodaron & $\begin{array}{l}150 \mathrm{mg} \text { iv dalam } 10 \text { menit, } \\
\text { dapat diulang } 10 \text { menit, } \\
\text { maintenance } 360 \mathrm{mg} \text { dalam } 6 \\
\text { jam dan } 540 \mathrm{mg} \text { dalam } 18 \text { jam } \\
\text { berikutnya }\end{array}$ & $\begin{array}{l}\text { Takikardia ventrikuler, } \\
\text { fibrilasi ventrikuler }\end{array}$ \\
\hline Digoxin & $\begin{array}{l}8-12 \mathrm{mcg} / \mathrm{kg} \text { (dosis loading); } \\
\text { berikan setengah dosis } \\
\text { loading dan } 1 / 4 \text { dosis loading } \\
\text { setelahnya dalam } 6-8 \text { jam }\end{array}$ & Fibrilasi atrium \\
\hline Diltiazem & $0.25 \mathrm{mg}$ iv dalam 2 menit & Fibrilasi atrium \\
\hline Furosemid & $1-2 \mathrm{mg} / \mathrm{kg}$ & Gagal jantung akut \\
\hline Lidokain & $1 \mathrm{mg} / \mathrm{kg}$ & Ektopik ventrikuler \\
\hline Dopamin & $5-15 \mathrm{mcg} / \mathrm{kg} / \mathrm{menit}$ & Hipotensi \\
\hline Dobutamin & $5-15 \mathrm{mcg} / \mathrm{kg} / \mathrm{menit}$ & Hipotensi \\
\hline Norepinefrin & $2-4 \mathrm{mcg} / \mathrm{menit}$ & Hipotensi \\
\hline Nitrogliserin & $5 \mathrm{mcg} / \mathrm{menit}$ & Hipertensi \\
\hline Adenosin & $\begin{array}{l}6 \mathrm{mg} \text { dalam } 1-3 \text { detik diikuti } \\
\text { bolus } 20 \mathrm{cc} \text { salin, dapat } \\
\text { diulang } 1-2 \text { detik } 12 \mathrm{mg}\end{array}$ & Takikardi supraventrikuler \\
\hline
\end{tabular}

\section{PUASA}

Puasa sebelum menjalani prosedur penting untuk menghindari risiko aspirasi terutama pada anestesi umum. Menurut American Society of Anesthesiologists (ASA), pasien masih dapat mengkonsumsi cairan jernih seperti air mineral hingga 2 jam sebelum prosedur, air susu ibu (ASI) hingga 4 jam. Makanan ringan, susu dari hewan, serta formula untuk bayi dapat dikonsumsi hingga 6 jam dan tidak boleh mengkonsumsi makanan berlemak serta minuman beralkohol minimal 8 jam sebelum prosedur. Selama pasien puasa, perlu dipertimbangkan pemberian cairan intravena sesuai kebutuhan untuk mencegah pasien berada dalam kondisi hipovolemik. Pada kasus emergensi, puasa mungkin tidak dapat dilakukan, sehingga prosedur intubasi dengan rapid sequence induction perlu dipertimbangkan untuk mengurangi risiko aspirasi. ${ }^{8}$

\section{PREMEDIKASI DAN MEDIKASI}

Pemberian obat-obatan premedikasi dilakukan sesuai dengan evaluasi dari anestesiolog terkait prosedur yang akan dilakukan. Obat premedikasi berfungsi untuk memperlancar induksi anestesia. Obat golongan benzodiazepin (mis. Midazolam $0.5 \mathrm{mg} / \mathrm{kgBB}$ ) dapat diberikan. ${ }^{9}$ Obat premedikasi yang diberikan harus diperhatikan agar tidak memiliki interaksi yang buruk dengan 
obat yang sudah dikonsumsi oleh pasien. Medikasi adalah obat-obatan yang sudah dikonsumsi oleh pasien berdasarkan anjuran klinisi yang memberikan pelayanan. Secara umum, obat antihipertensi seperti penghambat beta dapat dilanjutkan hingga pada hari pelaksanaan prosedur. Keputusan penghentian obat sebelum tindakan ditentukan berdasarkan status hemodinamika pasien, fungsi jantung, dan volume intravaskular. ${ }^{10}$

\section{MONITORING}

Pemantauan selama prosedur diperlukan untuk mengetahui status hemodinamika pasien dilihat dari tanda-tanda vital serta memantau komplikasi yang dapat terjadi. Komplikasi yang mungkin terjadi antara lain adanya cidera pada pleksus brakialis akibat hiperekstensi lengan di atas kepala untuk kebutuhan pencitraan serta obstruksi jalan napas. ${ }^{9}$

\section{TEKNIK ANESTESIA}

Pemilihan teknik anestesia harus menyesuaikan dengan prosedur yang akan dijalankan, durasi, serta umur pasien. Teknik anestesi yang dipakai haruslah bertujuan untuk menjaga stabilitas hemodinamika pasien serta meminimalisir efek anestesi pada sistem kardiovaskular yang dapat ketidaktepatan pengukuran pada prosedur diagnostik. ${ }^{4}$ Koordinasi dengan kardiologis dalam menentukan teknik anestesi juga penting untuk dilakukan agar prosedur dapat berjalan baik. Untuk teknik sedasi, obat-obatan seperti midazolam, propofol, ketamin, morfin, fentanil, dapat digunakan sesuai kondisi pasien. Tipe anestesia yang dapat dilakukan meliputi perawatan anestesia yang dipantau, anestesi umum, serta anestesi regional. Anestesi umum dapat dipertimbangkan jika durasi prosedur panjang serta membutuhkan pengaturan ventilasi. Anestesi regional dapat diberikan jika prosedur dilakukan pada ekstrimitas bawah.

\section{Implantasi katup aortik transkateter (IKAT)}

Pasien dengan stenosis katup aortik dengan usia lanjut dan komorbid berisiko untuk menjalani operasi penggantian katup tradisional. Prosedur anestesi pada IKAT dapat dilakukan dengan sedasi ringan, sedang, berat, maupun anestesi umum melalui jalur intravena menggunakan propofol dan remifentanil. Selama prosedur, anestesiolog yang berpengalaman dapat memantau fungsi ventrikel dan preload menggunakan ekokardiografi transesofagal. Komplikasi yang dapat terjadi selama prosedur antara lain adalah hiperkarbia karena penurunan tonus otot faringeal, hipertensi pulmonal, gagal jantung kanan. ${ }^{5,11,12}$

\section{Angiografi koroner dan intervensi perkutan}

Pada prosedur ini, anestesi lokal dapat diberikan dengan tambahan sedasi ringan. Namun, anestesiologis dibutuhkan dalam kondisi pasien mengalami distress pernapasan serta hemodinamika yang tidak stabil (mis. pada infark miokard akut). Peran anestesiologis juga diperlukan pada kondisi gagal sedasi dan sedasi berlebihan. ${ }^{13}$

\section{Prosedur pada anomali kongenital}

Pada keadaan defek septum, anestesi umum dengan intubasi endotrakeal menjadi pilihan terutama karena prosedur yang kompleks, durasi yang panjang, serta pada pasien yang mempunyai gangguan kognitif. Propofol dapat digunakan sebagai agen induksi dan sevofluran merupakan pilihan untuk gas anestesi. Pada prosedur ini, penggunaan ekokardigorafi 
transesofagal sering digunakan dan manuver pemeriksaan harus memperhatikan kemungkinan terjadinya ekstubasi secara tidak sengaja. ${ }^{14}$ Perlu diperhatikan komplikasi pasca prosedur setelah pemberian sedasi atau anestesi umum yang dapat terjadi seperti bronkospasme, aspirasi, hipotensi, mual, dan muntah. ${ }^{15}$

\section{Implantasi alat pacu jantung dan defibrillator kardioverter}

Pemasangan alat pada jantung dapat dilakukan dengan menggunakan anestesi lokal dengan sedasi sadar ataupun ringan. Untuk keperluan uji alat defibrilator pasca pemasangan, dapat dilakukan dengan anestesia umum ataupun sedasi yang dalam oleh anestesiolog. Midazolam dapat digunakan sebagai agen untuk sedasi dalam kondisi pasien sadar. ${ }^{16}$ Studi oleh Kaya et al. menunjukkan penggunaan teknik lokal anestesi dengan sedasi sadar aman dan layak untuk prosedur implantasi alat pada jantung baik termasuk pada prosedur yang kompleks. Perlu diperhatikan penggunaan analgesik dengan dosis tinggi untuk terapi nyeri pasca prosedur terutama pada wanita dibandingkan dengan pria. ${ }^{17,18}$

\section{Studi elektrofisiologis}

Sedasi ringan hingga sedang dapat digunakan pada studi elektrofisiologi. Namun, perlu pertimbangan terhadap durasi yang lama adanya periode aritmia yang membuat pasien tidak nyaman. Jika memerlukan anestesi umum, perlu diperhatikan penggunaan agen anestesi dan efeknya terhadap sistem konduksi. Anestesi umum dapat dilakukan pada pasien yang memerlukan intubasi serta adanya komorbid penyakit kardiovaskular yang signifikan. ${ }^{19}$ Propofol adalah agen anestesi pilihan baik untuk sedasi maupun anestesi umum karena memiliki efek minimal pada interval QT dan sistem konduksi. Penggunaan gas volatile seperti sevofluran dapat memperpanjang interval QT dan propofol dapat digunakan untuk membalikkan efek tersebut. $^{20}$

\section{PERSPEKTIF KARDIOLOGIS}

Prosedur intervensi yang dilakukan di LKK semakin maju dan kompleks dan memiliki kelebihan untuk pasien dengan risiko tinggi menjalani operasi. Kemajuan prosedur ini juga membutuhkan peran anestesiologis untuk berkolaborasi dalam perawatan pasien. Pasien yang menjalani prosedur di LKK sangat bervariasi dan dapat merupakan neonatus hingga pasien dengan usia lanjut dengan berbagai derajat kondisi klinis. Anestesiologis memegang peranan penting dalam memberikan layanan anestesi, memantau kondisi hemodinamika pasien, serta dapat melakukan tindakan lain seperti ekokardiografi transesofagal. ${ }^{4}$ LKK merupakan lingkungan kerja yang familiar bagi kardiologis, namun belum tentu bagi seorang anestesiologis. Pendekatan khusus perlu dilakukan. Seorang anestesiologis perlu memahami tata letak dan lingkungan kerja LKK seperti lokasi alat emergensi seperti defibrillator/kardioverter, lokasi alat-alat penunjang jalan napas, serta lokasi obatobatan emergensi. ${ }^{21}$

Pada prosedur yang membutuhkan peralatan fluoroskopi dan meja fluoroskopi perlu dikontrol oleh kardiologis secara mobil, sehingga anestesiologis dapat menyesuaikan peralatan dengan menggunakan jalur intravena yang panjang, tabung oksigen ekstra, serta sirkuit pernapasan yang memungkinkan pergerakan instrumen fluoroskopi. ${ }^{2}$ Risiko paparan radiasi juga menjadi hal yang patut diperhatikan. 
Semua personil kesehatan perlu meminimalisir paparan radiasi dengan mengikuti 3 prinsip, yaitu memaksimalkan jarak dari sumber radiasi, mengurangi durasi paparan, serta menggunakan proteksi yang adekuat. Panduan mengenai paparan radiasi dapat mengikuti prinsip ALARA (As Low As Reasonably Achievable). ${ }^{22}$

Keamanan dan keluaran yang baik adalah tujuan yang harus dicapai dalam menjalani prosedur di LKK. Kardiologis dan anestesiologis perlu saling berkomunikasi dalam mendiskusikan prosedur, risiko, dan strategi yang akan dijalankan. Perbedaan perspektif perlu dipertimbangkan dan perlu saling menghargai batasan lingkungan kerja masing-masing ahli untuk mencapai tujuan. $^{23}$ Sebuah studi di India menjelaskan bahwa LKK dapat menyebabkan ketidaknyamanan untuk seorang anestesiologis melakukan prosedur yang efektif. Studi ini juga menyarankan beberapa faktor yang dapat memperbaiki efektivitas kinerja di dalam LKK. Beberapa saran tersebut adalah komunikasi antara kardiologis dan anestesiologis selama pra-prosedural dan intra-prosedur; disiplin dalam hal jadwal pelaksanaan prosedur, persiapan pasien, dan dokumentasi dokumen pasien; ketersediaan dan perawatan rutin peralatan anestesi; perlunya staf yang terlatih untuk membantu prosedur risiko tinggi; pemantauan radiasi; pelatihan untuk anestesiologis dan asisten anestesi terhadap lingkungan LKK. ${ }^{24}$

\section{RINGKASAN}

Kebutuhan prosedur diagnostik dan terapeutik di LKK semakin meningkat seiring dengan meningkatnya prevalensi penyakit jantung. Peran anestesiologis dalam prosedur diagnostik dan terapeutik di LKK sangat penting baik dalam kondisi elektif dan emergensi.
Pemahaman terhadap patofisiologi dan prosedur terkait sangat penting untuk menunjang keberhasilan tindakan. Pelatihan terhadap anestesiolog di lingkungan LKK diperlukan untuk meningkatkan kemampuan perawatan. Peran anestesiolog bersama kardiolog dan tim LKK yang baik dapat menurunkan tingkat morbiditas dan mortalitas pasien terutama pada kondisi kompleks.

\section{DAFTAR PUSTAKA}

1. Roth GA, Johnson C, Abajobir A, Abd-Allah F, Abera SF, Abyu G, et al. Global, regional, and national burden of cardiovascular diseases for 10 causes, 1990 to 2015. J Am Coll Cardiol. 2017;70(1):1-25

2. Thangavel $\mathrm{P}$, Muthukamar S, Kathekeyan BR, Vakamudi M, Ashokkumar, Nayagam $\mathrm{H}$ et al. Anaesthetic challenges in cardiac interventional procedures. World J Cardiovasc Surg. 2014;4:206-216

3. Ladouceur VB, Lawler PR, Gurvitz M, Pilote L, Eisenberg MJ, IonescuIttu R, et al. Exposure to low dose ionising radiation from cardiac procedures in patients with congenital heart disease. Circulation. 2016;133:12-20

4. Kemp MEA. Anaesthesia and the cardiac catheterisation laboratory. South Afr J Anaesth Analg. 2018;24(3)

5. Braithwaite S, Kluin J, Buhre WF, de Waal EEC. Anaesthesia in the cardiac catheterization laboratory. Curr Opin Anaesthesiol. 2010;23(4):507-512

6. Shetti AN, Karigar SL, Mustilwar RG, Singh DR, Nag K. Anesthesiologist in catheterization laboratories; the roles and goals!! a postgraduate educational review. Anesth Essays Res. 2017;11(4):1129 
7. Haddy S. Anesthesia for structural heart interventions. Cardiol Clin. 2013;31(3):455-465

8. Apfelbaum J. Practice guidelines for preoperative fasting and the use of pharmacologic agents to reduce the risk of pulmonary aspiration: application to healthy patients undergoing elective procedures an updated report by the american society of anesthesiologists committee on standards and practice parameters. Anesthesiology. 2011;114(3):495

9. Reddy K, Jaggar S, Gillbe C. The anaesthetist and the cardiac catheterisation laboratory. Anaesthesia. 2006;61(12):11751186

10. Wijeysundera DN, Duncan D, Nkonde-Price C, Virani SS, Washam JB, Fleischmann KE, et al. Perioperative beta blockade in noncardiac surgery: a systematic review for the 2014 acc/aha guideline on perioperative cardiovascular evaluation and management of patients undergoing noncardiac surgery: a report of the american college of cardiology/american heart association task force on practice guidelines.

Circulation. 2014;130:2246-2264

11. Ben-Dor I, Goldstein SA, Pichard AD, Satler LF, Maluenda G, Li Y, et al. Clinical profile, prognostic implication, and response to treatment of pulmonary hypertension in patients with severe aortic stenosis. Am J Cardiol 2011;107:1046-51

12. Minai OA, Yared JP, Kaw R, Subramaniam K, Hill NS. Perioperative risk and management in patients with pulmonary hypertension. Chest 2013;144:32940

13. Hamid A. Anesthesia for cardiac catheterization procedures. Heart Lung Vessel. 2014;6(4):225-231

14. Junghare SW, Desurkar V. Congenital heart diseases and anaesthesia. Indian J Anaesth. 2017;61(9):744-752

15. Lam JE, Lin EP, Alexy R, Aronson LA. Anesthesia and the pediatric cardiac catheterization suite: A review. Paediatr

Anaesth. 2015;25:127-34

16. Theron $\mathrm{P}$, Guha $\mathrm{K}$, Mantziari L, Salahuddin S, Sharma R, Jaggar S. General Anesthesia Versus Sedation for Implantation of a Biventricular Pacing Device for Cardiac Resynchronization Therapy. J Cardiothorac Vasc Anesth. 2014;28:280-284

17. Bode K, Breithardt OA, Kreuzhuber M, Mende M, Sommer P, Richter S, et al. Patient discomfort following catheter ablation and rhythm device surgery. Europace. 2015;17:1129_ 1135

18. Kaya E, Südkamp H, Lortz J, Rassaf T, Jánosi RA. Feasibility and safety of using local anaesthesia with conscious sedation during complex cardiac implantable electronic device procedures. Sci Rep. 2018;8(1):7103

19. Yildiz M, Yilmaz-Ak H, Oksen D, Oral S. Anesthetic management in electrophysiology laboratory: a multidisciplinary review. J Atr Fibrillation. 2018;10(5):1775

20. Terao Y, Higashijima U, Toyoda T, Ichinomiya T, Fukusaki M, Hara T. The effects of intravenous anesthetics on qt interval during anesthetic induction with sevoflurane. J

Anesth. 2016;30(6):929-934 
21. Shook DC, Savage RM. Anesthesia in the cardiac catheterization laboratory and electrophysiology laboratory. Anesthesiol Clin. 2009;27(1):47-56

22. Sutton NJ, Lamour J, Gellis LA, Pass RH. Pediatric patient radiation dosage during endomyocardial biopsies and right heart catheterization using a standard "alara" radiation reduction protocol in the modern fluoroscopic era. Catheter Cardiovasc Interv. 2014;83(1):80-83

23. Odegard KC, Vincent R, Baijal RG, Daves SM, Gray RG, Javois AJ, et al. SCAI/CCAS/SPA expert consensus statement for anesthesia and sedation practice: recommendations for patients undergoing diagnostic and therapeutic procedures in the pediatric and congenital cardiac catheterization laboratory. Anesth Analg. 2016;123(5):1201-1209

24. Annachhatre AS, Janbure N, Gaddam N, Shinde D, Annachhatre S. Anesthesiologists and job satisfaction in cardiac cath lab: do we need guidelines?. Ann Card Anaesth. 2020;23(2):116-121 